\title{
Prevention of Chronic Experimental Pyelonephritis by Suppression of Acute Suppuration
}

\author{
Michel Pierre Glauser, Joseph M. Lyons, and Abraham I. Braude, Départment \\ de Médecine, Centre Hospitalier Universitaire Vaudois, 1011 Lausanne, \\ Switzerland, and Departments of Medicine and Pathology, University of \\ California, San Diego, School of Medicine, University Hospital, San Diego, \\ California 92103
}

\begin{abstract}
A B S T R A C T In order to evaluate the importance of suppuration, persistent infection, and scar formation in the evolution of Escherichia coli chronic pyelonephritis, we treated rats with different antibiotic regimens at different stages of the disease. The results show that $(a)$ if acute suppurative pyelonephritis is aborted with early antibiotic therapy, chronic pyelonephritis is prevented; $(b)$ chronic pyelonephritis can develop even after eradication of infection if acute suppuration persists beyond 3 days; $(c)$ persistent infection does not lead to chronic pyelonephritis, if the acute suppuration is suppressed; and $(d)$ residual infection, antigen-load, antibody, and(or) cell-dependent autoimmune processes did not play a significant role.

We interpret these results as evidence that the pathologic entity recognized as chronic pyelonephritis results from kidney damage, scarring, and shrinkage secondary to acute suppuration.
\end{abstract}

\section{INTRODUCTION}

While interstitial nephritis is often caused by analgesic's and metabolic or vascular disturbances (1), end-stage kidneys may result from infection (chronic pyelonephritis), especially in the presence of structural urinary abnormalities $(2,3)$. Since chronic pyelonephritic kidneys are often sterile (4-7), mechanisms other than bacterial infection have been postulated in the pathogenesis of this disease. Suggestions have been made that the progressive renal damage of chronic pyelonephritis may be due to the survival of bacterial protoplasts (8) or to the persistence of bacterial antigens within the lesions $(5,9)$. The demonstration within pyelonephritic kidneys of antibody synthesis directed against the antigens of the infecting organisms $(10,11)$ has raised the possibility that antigen-antibody com-

Received for publication 13 June 1977 and in revised form 21 September 1977. plexes might trigger continuous inflammation. Common antigens shared by some strains of Escherichia coli and kidney tissue (12) have been implicated as a possible mechanism of autoimmune phenomena. Others have suggested that the chronic renal scarring of pyelonephritis is the result of previous inflammation and tissue destruction occurring during the acute suppurative phase (13).

In order to examine the relative importance of infection, inflammation, and scarring in the evolution of chronic pyelonephritis, an attempt was made in this study to dissociate these processes by administering antibiotics at different stages of the disease. We have used a rat model of obstructive retrograde $E$. coli pyelonephritis (14) that resembles human pyelonephritis.

\section{METHODS}

Pyelonephritis. Acute retrograde pyelonephritis was produced in male Wistar-Lewis rats $(225-250 \mathrm{~g})$ (Charles River Breeding Laboratories, Inc., Wilmington, Mass.), as described previously (14), with slight modification. Briefly, after water deprivation for $18 \mathrm{~h}$, animals were anesthetized with ether before exposing the left ureter through a midline incision of the abdominal wall. At midureter level, a silk suture was passed through the flank into the peritoneal cavity, then over the ureter, and out again to the left flank. The ligature was left loosely in place while bacteria were injected through the dome of the bladder into the lumen. The bacterial inoculum of $2 \times 10^{3}$ organisms of an overnight culture of E. coli 06 (Williams) in trypticase soy broth $(\mathrm{TSB})^{1}$ (obtained like all other microbiological culture media in this study from BBL, division of Becton, Dickinson \& Co., Cockeysville, Md.) was gently infused in a volume of $1.0 \mathrm{ml}$. By injecting TSB colored with trypan blue into the bladder while visualizing the ureters, we demonstrated that reflux consistently occurred when urine appeared at the external urethral meatus. The remainder of the $1.0 \mathrm{ml}$ volume was passed externally through the urethra without causing further bladder distension. After the infusion, the two arms of the ureteral ligature were tied loosely and the

${ }^{1}$ Abbreviation used in this paper: TSB, trypticase soy broth. 
abdominal wall was closed. $20 \mathrm{~h}$ later, the animals were lightly anesthetized and the ligature was cut from the outside and carefully removed. The incidence of gross pyelonephritis was approximately $75 \%$. Residual hydronephrosis was invariably present in the pyelonephritic kidneys.

Antibiotic treatment. In order to evaluate the relationship of acute pyelonephritis to chronic pyelonephritis, groups of rats were treated $28-30 \mathrm{~h}, 3$ days, 5 days, and 12 days after infection. To achieve sterility of the kidneys, each group was treated for 10 days with the combination of ampicillin and gentamicin and sacrificed 75-90 days after infection. Ampicillin was given intramuscularly every $6 \mathrm{~h}$ in a dose of $160 \mathrm{mg} / \mathrm{kg}$ per day, and gentamicin intramuscularly every $12 \mathrm{~h}$ in a dose of $8 \mathrm{mg} / \mathrm{kg}$ per day. We found that the serum levels $1 \mathrm{~h}$ after one injection of each drug were similar to those observed in humans $(6.5 \mu \mathrm{g} / \mathrm{ml}$ for ampicillin, $4.6 \mu \mathrm{g} / \mathrm{ml}$ for gentamicin). Control animals received i.m. injections of saline every $6 \mathrm{~h}$. It was established that the combination of ampicillin and gentamicin in these doses can sterilize the kidneys of all the animals by 10 days if the treatment is started $28-30 \mathrm{~h}$ after infection. In addition, the effectiveness of this regimen was also established when treatment was started when kidney suppuration was at its peak ( 5 days, Fig. 1).

In order to investigate the role of persistent infection in the development of chronic pyelonephritis, we treated rats with ampicillin alone in the same dosage and intervals between injections as for combined therapy. Treatment began 28-30 h after infection, but lasted for only 3.5 days. This regimen prevented further development of acute pyelonephritis while allowing a substantial amount of infection to remain in the kidney (partial treatment).

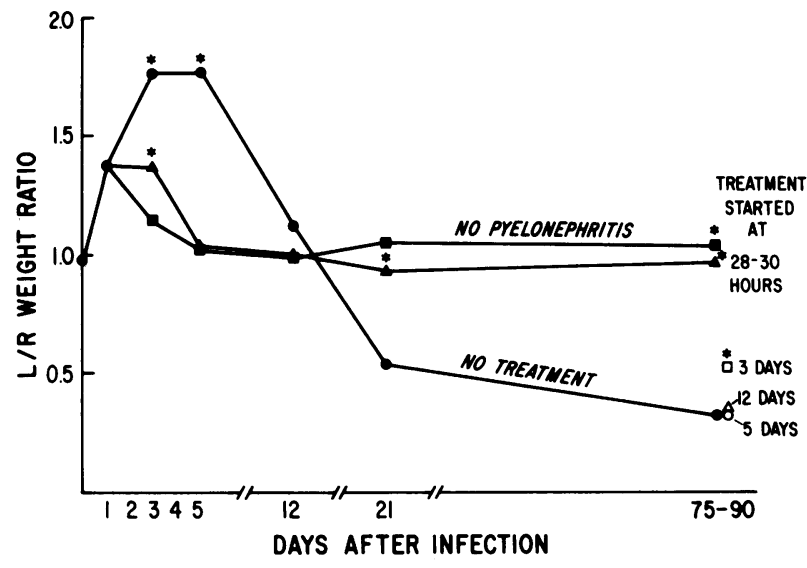

FIGURE 1 Effect of starting treatment of acute pyelonephritis at different times on the development of chronic pyelonephritis. The severity of acute and chronic pyelonephritis was measured quantitatively by determining kidney weights and expressed as the ratio of left kidney over right kidney weight ( $\mathrm{L} / \mathrm{R}$ weight ratio). The suppuration during acute pyelonephritis causes an increase in the $L / R$ weight ratio, while the destruction of kidney parenchyma with compensatory right kidney hypertrophy during chronic pyelonephritis causes a decrease in the $L / R$ weight ratio. All treated animals received ampicillin and gentamicin for 10 days starting at $28-30 \mathrm{~h}(\boldsymbol{\Delta}), 3$ days $(\square), 5$ days $(\bigcirc)$, and 12 days $(\triangle)$. Control animals which received saline are designated by $\bullet$. Animals which did not develop pyelonephritis (no pyelonephritis) are designated by a. Each point represents the mean of $8-26$ animals. The points with an asterisk indicate a significant difference $(P<0.0025)$ from the next point below it.
Evaluation of the severity of pyelonephritis. Kidney weight provides the best quantitative measure of pyelonephritis. In acute pyelonephritis, kidney weight increases in proportion to the suppuration, while in chronic pyelonephritis its decline reflects the amount of kidney destruction (15). We have used the ratio of the weights of the left kidney over the right kidney ( $\mathrm{L} / \mathrm{R}$ weight ratio) in order to minimize the variation of kidney weights between animals. This is especially important when one deals with long-term experiments, where total body weights between animals may vary greatly. In addition, in the chronic phase of pyelonephritis, the $L / R$ weight ratio also expresses the hypertrophy of the right kidney that compensates for destruction and shrinkage of the left kidney (15).

Animals were sacrificed 75-90 days after initiation of infection, at a time when chronic pyelonephritis in this model is well-established (15). Treated and untreated rats were also sacrificed earlier at different times during and after treatment in order to delineate further the evolution of acute to chronic pyelonephritis. After terminal anesthesia, the animals were bled by cardiac puncture. The abdomen was opened; the kidneys were removed aseptically, observed for gross pathological lesions, weighed, and cut in half; one half was homogenized in $1 \mathrm{ml}$ of TSB, and the other half was processed for histologic examination. Tenfold dilutions of the homogenates were made and $0.5 \mathrm{ml}$ plated on trypticase soy agar plates containing $1,000 \mathrm{U}$ of penicillinase per $\mathrm{ml}$. The plates were incubated overnight aerobically at $37^{\circ} \mathrm{C}$ and the number of colony-forming units counted. When high levels of gentamicin were expected (16), the plates were incubated in anaerobic jars (Gaspack catalyst, BBL) for $48 \mathrm{~h}$ to decrease gentamicin activity (17).

Antibody determinations. Bacteria were grown in TSB for $36 \mathrm{~h}$ at $37^{\circ} \mathrm{C}$. Formalin was then added to a final concentration of $1 \%$ and the culture reincubated overnight at $37^{\circ} \mathrm{C}$. The cells were harvested by centrifugation, washed three times in normal saline, and resuspended in saline to half the original volume of broth.

Serum antibody levels were measured by bacterial agglutination with microtiter equipment (Microtiter, Cooke Laboratory Products Div., Dynatech Laboratories Inc., Alexandra, Va.). Twofold serial dilutions of serum in $0.05 \mathrm{ml}$ of saline were made in plastic disposable microtiter plates (V-type), to which was added an equal volume $(0.05 \mathrm{ml})$ of bacterial suspension. Plates were gently agitated, covered with sealing tape, and incubated for $2 \mathrm{~h}$ at $37^{\circ} \mathrm{C}$ and overnight at $8^{\circ} \mathrm{C}$. The titer of a specimen was the highest dilution causing bacterial agglutination.

Statistical evaluation. L/R weight ratio, number of viable bacteria per gram of kidney, and serum titers of treated and control animals were compared for significance by Student's unpaired $t$ test.

\section{RESULTS}

\section{Effect of starting combined treatment at different} times on the development of chronic pyelonephritis. The effectiveness of the combined therapy in sterilizing the kidneys when started $28-30 \mathrm{~h}$ after infection or at the peak of suppuration (5 days, Fig. 1) was determined in rats sacrificed at completion of the 10-day treatment. All of eight rats had sterile kidneys when treatment was started at $28-30 \mathrm{~h}$ and only 1 of 10 showed persistent low-grade infection when treatment was started at 5 days of infection. The efficacy of such 
treatment was further emphasized by the fact that none of 44 rats treated with the combination started at different times during infection had viable organisms in their kidneys at 75-90 days. By contrast, 10/17 kidneys of untreated controls yielded E. coli 06 in culture.

Fig. 1 shows the evolution of untreated pyelonephritis as defined by the $L / R$ weight ratio. The period of maximum exudation and suppuration occurred 3 days after onset of infection and lasted until day 5. Kidney weight showed a drop during the following $2 \mathrm{wk}$, and by day 21 the $\mathrm{L} / \mathrm{R}$ ratio was already $50 \%$ less then that observed in nonpyelonephritic animals. When sacrificed 75-90 days after initiation of infection, the macroscopic and microscopic appearance of the untreated kidneys did not differ from that described previously: the left kidneys were severely scarred and shrunken and showed the same changes of chronic pyelonephritis presented in earlier descriptions of this model (15). 10 of 17 kidneys of untreated rats were still infected at that time, and the average $L / R$ weight ratio was 0.316 , compared to 1.040 in 14 nonpyelonephritic kidneys $(P<0.0005)$. Among untreated rats there was no difference between the mean $\mathrm{L} / \mathrm{R}$ ratio of those with infected and those with sterile kidneys.

If combined therapy was started $28-30 \mathrm{~h}$ after onset of infection, it prevented further exudation and suppuration in the kidney. As seen in Fig. 1, dramatic protection against chronic pyelonephritis resulted at 75-90 days. A few tiny depressions were seen on the surface of the left kidney, and their $\mathrm{L} / \mathrm{R}$ weight ratio was only $8 \%$ below that of nonpyelonephritic kidneys $(P<0.005)$.

If treatment was started 3 days after infection, when acute suppuration reaches its peak, $50 \%$ of the left kidney was destroyed by chronic pyelonephritis at 75-90 days as judged by gross examination and by the
$\mathrm{L} / \mathrm{R}$ weight ratio $(P<0.005$ in comparison to untreated rats or to rats treated at $28-30 \mathrm{~h}$ ).

If treatment was started 5 days after infection, when maximal suppuration had lasted for 2 days, the sterile chronic pyelonephritic kidneys were indistinguishable macroscopically, microscopically, and in the degree of kidney shrinkage from untreated animals. (L/R weight ratio: $P<0.0005$ in comparison to rats treated at 3 days). The $\mathrm{L} / \mathrm{R}$ weight ratio was $70 \%$ below that of nonpyelonephritic kidneys. The same observations were made when treatment was started 12 days after infection (Fig. 1).

Protection from chronic pyelonephritis after partial treatment with ampicillin alone started at 28$30 \mathrm{~h}$. Ampicillin given $28-30 \mathrm{~h}$ after infection and continued for 3.5 days reduces suppuration in acute pyelonephritis, although a substantial number of organisms remain in the kidney (partial treatment). The average $L / R$ weight ratio was 1.159 after treatment compared to 1.767 in nontreated control rats $(P$ $<0.0005)$, while the mean number of viable bacteria recovered was $1.16 \times 10^{5}$ in 12 rats. When rats were sacrificed 75-90 days after partial treatment, 6/14 kidneys were still infected, an incidence not significantly different from untreated rats (10/17). Furthermore, the mean number \pm 1 SEM of bacteria per gram of infected kidney was not different after partial treatment $\left(8.51 \times 10^{4} \pm 3.0\right)$ from untreated controls $\left(1.29 \times 10^{5} \pm 0.3\right)$. However, a striking difference in the degree of pyelonephritis was seen: The mean $L / R$ weight ratio (Table I) and the gross and microscopic appearances of infected kidneys showed protection when compared with the shrunken and distorted kidneys of untreated animals. Their $\mathrm{L} / \mathrm{R}$ weight ratio was only $23 \%$ below that of nonpyelonephritic kidneys $(P<0.005)$, and $15 \%$ below that of sterile kidneys after

TABLE I

Protection against Chronic Pyelonephritis by Antibiotics: Treatment Started 28-30 h after Onset of Infection

\begin{tabular}{|c|c|c|c|c|c|}
\hline Group & Treatment & $\begin{array}{c}\text { Chronic } \\
\text { pyelonephritis }\end{array}$ & $\begin{array}{l}\text { E. coli } 06 \\
\text { cultured from } \\
\text { kidney }\end{array}$ & $\begin{array}{l}\text { Total } \\
\text { number of } \\
\text { rats }\end{array}$ & $\begin{array}{l}\text { Left kidney damage: } \\
\text { severity }=\mathrm{L} / \mathrm{R} \\
\text { kidney weight } \\
(\text { mean } \pm \mathrm{SD})\end{array}$ \\
\hline Controls* & None & () & () & 14 & $1.04 \pm 0.07$ \\
\hline Pyelonephritic controls & None & + & $\begin{array}{l}0 \\
+\end{array}$ & $\begin{array}{r}7 \\
10\end{array}$ & $\begin{array}{l}0.35 \pm 0.26 \\
0.35 \pm 0.16\end{array}$ \\
\hline Partial treatment & Ampicillin 3.5 days & + & $\begin{array}{l}0 \\
+\end{array}$ & $\begin{array}{l}8 \\
6\end{array}$ & $\begin{array}{l}0.94 \pm 0.08 \\
0.80 \pm 0.12\end{array}$ \\
\hline Combined treatment & Ampicillin + Gentamicin 10 days & + & () & 14 & $0.95 \pm 0.08$ \\
\hline
\end{tabular}

Following L/R weight ratios were significantly different: (a) sterile versus infected kidneys after ampicillin alone $(P<0.0125)$; $(b)$ infected kidneys after ampicillin alone versus pyelonephritic controls $(P<0.0005)$; $(c)$ combined treatment versus pyelonephritic controls $(P<0.0005)$.

* Inoculated rats that developed no evidence of kidney infection or pyelonephritis. 
partial treatment $(P<0.0125)$. Sterile kidneys after partial treatment had a $\mathrm{L} / \mathrm{R}$ weight ratio similar to that of kidneys after combined treatment started at 28-30 h.

Effect of treatment on antibody titers. Table II gives the mean antibody titers 75-90 days after infection. The titers of rats treated after the third day of infection with ampicillin and gentamicin and rats with infected kidneys after partial treatment were similar to those of untreated control animals. By contrast, the titers of animals whose kidneys were sterile because treatment was started at $28-30 \mathrm{~h}$ with combined drugs for 10 days or ampicillin for 3.5 days were significantly lower.

\section{DISCUSSION}

From the results observed with the different antibiotic regimens and the variable times of initiating treatment, it is possible to draw some conclusions about the relationship of acute to chronic pyelonephritis. First of all, chronic pyelonephritis can evolve from acute pyelonephritis in the absence of persistent infection. This was evident from the unrestrained progression to chronic pyelonephritis after acutely inflamed kidneys were sterilized at 3 or 5 days by combined treatment with ampicillin and gentamicin. Secondly, if suppuration is reduced during the acute stage by ampicillin alone, there is a corresponding reduction in the severity of chronic pyelonephritis despite persisting infection. Finally, if acute suppurative pyelonephritis is aborted with early combined therapy, chronic pyelonephritis is prevented.

We interpret these findings as strong evidence that chronic pyelonephritis is a consequence of acute suppurative necrosis with subsequent scarring. Cotran

\section{TABLE II}

Effect of Antibiotic Treatment on Antibody Response: E. Coli Agglutinins in Pyelonephritic Rats 75-90 Days after Infection

\begin{tabular}{lccc}
\hline \multicolumn{1}{c}{ Treatment } & $\begin{array}{c}\text { Start of } \\
\text { treatment } \\
\text { after } \\
\text { infection }\end{array}$ & $\begin{array}{c}\text { E. coli } 06 \\
\text { cultured } \\
\text { from kidney }\end{array}$ & $\begin{array}{c}\log _{2} \text { serum } \\
\text { titer (mean) }\end{array}$ \\
\hline None & - & + & 11.5 \\
Partial $(\mathrm{A} \times 3.5)^{*}$ & $28-30 \mathrm{~h}$ & + & $10.2 \ddagger$ \\
& $28-30 \mathrm{~h}$ & 0 & 6.1 \\
Combined $(\mathrm{A}+\mathrm{G} \times 10)^{*}$ & $28-30 \mathrm{~h}$ & 0 & $7.2 \ddagger$ \\
& 3 days & 0 & $10.2 \ddagger$ \\
& 5 days & 0 & 11.6 \\
& 12 days & 0 & 10.6 \\
\hline
\end{tabular}

$* \mathrm{~A}=$ ampicillin; $\mathrm{G}=$ gentamicin $; \quad \times 3.5=3.5$ days $; \quad \times 10$ $=10$ days.

\$ Significantly different $(P<0.025)$ from value next below.
(13) has suggested from histopathological studies that scarring in chronic pyelonephritis is mostly the result of tissue destruction during acute inflammation. Glassock et. al. (7) were unable to prevent interstitial and tubular alterations by eradicating enterococci with antibiotics started 23-36 wk after onset of infection, although the caliceal and papillary lesions were less severe. Sullivan et. al. (18) have reported that complement inactivation decreases the acute inflammation of pyelonephritis in the rat and reduces tissue damage. The ability of exudative leukocytes from pyelonephritic kidneys to destroy syngeneic kidney cells was established more recently by Williams et al. (19). Our observations, however, demonstrate for the first time the critical importance of suppuration during acute pyelonephritis on the outcome of chronic pyelonephritis.

Persistent infection is not a likely mechanism of kidney damage from chronic pyelonephritis, because viable bacteria are not required for the lesions to progress $(6,7)$. After partial treatment with ampicillin started at 28-30 h, we found a minor degree of kidney damage from chronic pyelonephritis. If persistent infection was the critical factor leading to chronic pyelonephritis, one would expect to see destruction and shrinkage in these kidneys of the same magnitude as that found in untreated rats, since the number of bacteria surviving in the kidneys was similar.

If persistent bacterial infection is not likely to contribute to the pathogenesis of chronic pyelonephritis, other mechanisms have been considered. Alterations in renal tissue antigenicity produced by endotoxin (20) or common antigens shared by E. coli and renal tissue (12) have been postulated as possible triggers for autoimmune phenomena; but demonstration of antikidney antibodies have been unsuccessful so far $(21$, 22). Thymus-dependent autoimmune phenomena are not important, since both neonataly thymectomized rats (23) and adult thymectomized irradiated rats (24) had a course of chronic pyelonephritis similar to that of control rats. We have reproduced these observations in our model in rats thymectomized at birth: They showed no difference in the extent of chronic pyelonephritis over that observed in sham-thymectomized rats.

The persistence of bacterial antigens in the late phase of pyelonephritis has been shown both in experimental and human kidney infections $(25,26,5)$. It has been suggested therefore that this could lead to the progression of the disease by a process involving antigenantibody complexes $(5,9)$. In our experiments, partially treated animals still infected at 2-3 mos demonstrated no significant difference in anti-E. coli 06 antibody titers when compared with untreated controls. If one assumes that antibody titers are to some extent a reflection of the antigenic stimulus, and if persistent bacterial antigens were to be responsible for continuous kidney destruction, one would expect to see as 
severe destruction in partially treated rats as in untreated controls (Table I). These negative results are in accordance with previous observations which clearly showed that the pyelonephritic process did not progress despite the persistence of large amounts of bacterial antigens $(25,26)$ and the continued local production of antibodies directed against these antigens $(10,11)$.

In contrast to man, the rat kidney possesses only one calyx, so that the pathological events in the whole rat kidney seem to mirror those in single or multiple human renal pyramids. If this is true, our observations in the rat strongly suggest that the pathologic entity recognized as chronic pyelonephritis results from kidney damage, scarring, and shrinkage secondary to acute suppuration. There are no indications that residual infection, antigenic load, or a thymusdependent autoimmune mechanism triggers a continuous destructive process leading to chronic pyelonephritis. Whether or not these ideas will be borne out by future studies, these observations further stress the need for prompt and effective antibiotic treatment during acute obstructive pyelonephritis.

\section{ACKNOWLEDGMENTS}

This work was supported by research grant 5R01-AI-12476-07, the Franz Joseph Foundation, and the American-Swiss Foundation for Scientific Exchange.

\section{REFERENCES}

1. Murray, T., and M. Goldberg. 1975. Chronic interstitial nephritis: etiologic factors. Ann. Intern. Med. 82: 453459.

2. Barnes, B. A., J. J. Bergan, W. E. Braun, J. F. Fraumeni, Jr., S. L. Kountz, M. R. Mickey, A. L. Rubin, R. L. Simmons, L. E. Stevens, and R. E. Wilson. 1973. The 11th report of the human renal transplant registry. J. Am. Med. Assoc. 226: 1197-1204.

3. Schechter, H., C. D. Leonard, and B. H. Scribner. 1971. Chronic pyelonephritis as a cause of renal failure in dialysis candidates. J. Am. Med. Assoc. 216: 514-517.

4. Angell, M. E., A. S. Relman, and S. L. Robbins. 1968. "Active" chronic pyelonephritis without evidence of bacterial infection. N. Engl. J. Med. 278: 1303-1308.

5. Aoki, S., S. Imamura, M. Aoki, and W. R. McCabe. 1969. "Abacterial" and bacterial pyelonephritis. Immunofluorescent localization of bacterial antigen. N. Engl. J. Med. 281: 1375-1382.

6. Kalmanson, G. M., S. C. Sommers, and L. B. Guze. 1965. Pyelonephritis. VII. Experimental ascending infection with progression of lesions in the absence of bacteria. Arch. Pathol. 80: 509-516.

7. Glassock, R. J., G. M. Kalmanson, and L. B. Guze. 1974. Pyelonephritis XVIII. Effect of treatment on the pathology of enterococcal pyelonephritis in the rat. Am.J. Pathol. 76: 49-60.

8. Guze, L. B., and G. M. Kalmanson. 1964. Persistence of bacteria in "protoplast" form after apparent cure of pyelonephritis in rats. Science (Wash. D. C.). 143: 1340-1341.

9. Strong, D. W., R. K. Lawson, and C. V. Hodges. 1974. Experimentally induced pyelonephritis using bacterial antigen and its prevention with immunosuppression. Invest. Urol. 11: 479-485.

10. Miller, T. E., and D. North. 1971. The cellular kinetics of the immune response in pyelonephritis.J. Lab. Clin. Med. 78: 891-904.

11. Spencer, A. G., and A. P. Fairhead. 1972. The cellular immune response in experimental Escherichia coli pyelonephritis in the rat. Nephron. 9: 325-336.

12. Holmgren, J., L. A. Hanson, S. E. Holm, and B. Kaijser. 1971. An antigenic relationship between kidney and certain Escherichia coli strains. Int. Arch. Allergy Appl. Immunol. 41: 463-474.

13. Cotran, R. S. 1969. Experimental pyelonephritis. In The Kidney: Morphology, Biochemistry, Physiology. C. Rouiller and A. F. Muller, editors. Academic Press Inc., New York. Vol. II. 269-361.

14. Brooks, S. J. D., J. M. Lyons, and A. I. Braude. 1974. Immunization against retrograde pyelonephritis. I. Production of an experimental model of severe ascending Escherichia coli pyelonephritis without bacteremia in rats. Am. J. Pathol. 74: 345-354.

15. Brooks, S. J. D., J. M. Lyons, and A. I. Braude. 1977. Immunization against pyelonephritis. III. Protection against chronic $E$. coli pyelonephritis by vaccination. $J$. Infect. Dis. 136: 633-639.

16. Luft, F. C., and S. A. Kleit. 1974. Renal parenchymal accumulation of aminoglucoside antibiotics in rats. $J$. Infect. Dis. 130: 656-659.

17. Verklin, R. M., and G. L. Mandell. 1977. Alteration of effectiveness of antibiotics by anaerobiosis. J. Lab. Clin. Med. 89: 65-71.

18. Sullivan, M. J., R. A. Harvey, and T. Shimamura. 1977. Experimental pyelonephritis: the role of polymorphonuclear leukocytes and complement system in structural damage to the rat kidney. Fed. Proc. 36: 1070.

19. Williams, T. W., J. M. Lyons, and A. I. Braude. 1977. In vitro lysis of target cells by rat polymorphonuclear leukocytes isolated from acute pyelonephritis exudates. J. Immunol. 119: 671-674.

20. Kovats, T. G. 1961. The role of endotoxin in autoimmune processes. Naturwissenschaften. 49: 572-573.

21. Kalmanson, G. M., and L. B. Guze. 1963. Pyelonephritis. An attempt to demonstrate anti-kidney antibody in the sera of patients with chronic bacteriuria. Am. J. Med. Sci. 246: 532-536.

22. Miller, T. E., J. W. Smith, J. W. Lehmann, and J. P. Sanford. 1970. Autoimmunity in chronic experimental pyelonephritis. J. Infect. Dis. 122: 191-195.

23. Coles, G. A., S. Chick, M. Hopkins, R. Ling, and N. J. Radford. 1974. The role of the $T$ cell in experimental pyelonephritis. Clin. Exp. Immunol. 16: 629-636.

24. Miller, T., S. Burnham, and G. Simpson. 1975. Selective deficiency of thymus-derived lymphocytes in experimental pyelonephritis. Kidney Int. 8: 88-97.

25. Sanford, J. P., B. W. Hunter, and P. Donaldson. 1962. Localization and fate of Escherichia coli in hematogenous pyelonephritis. J. Exp. Med. 116: 285-294.

26. Cotran, R. S. 1963. Retrograde Proteus pyelonephritis in rats. J. Exp. Med. 117: 813-821. 